\title{
COMER AL OTRO: RETORICAS DE LA ALIMENTACIÓN: UNA LECTURA DEL SEMINARIO INÉDITO MANGER L'AUTRE DE JACQUES DERRIDA $\left(1989\right.$ - 1990) ${ }^{1}$
}

Valeria Campos Salvaterra ${ }^{2}$

Resumen: en los seminarios inéditos dictados en Estados Unidos y Francia entre 1989 y 1991, Manger l'autre: Politiques de l'amitié y Rhétoriques du cannibalisme, J. Derrida analiza la función retórica que los textos filosóficos de la tradición occidental dan a la alimentación. En cuanto acto de incorporación de lo ajeno y traspaso de fronteras entre lo exterior y lo interior, comer ha sido utilizado como metáfora por excelencia para nombrar los procesos de comprensión e idealización, así como también la dinámica general de la relación con el otro. Sin embargo, esta función trópica de la alimentación alcanza, sostiene Derrida, incluso a la lógica misma del discurso filosófico, en cuanto inseparable de una cierta retoricidad que le es constitutiva. Analizamos dichas funciones mostrando que son transversales a la filosofía en general y especiales temas de la obra de Derrida en todas sus épocas textuales.

Palabras-clave: Derrida. Canibalismo. Metáfora. Comida. Filosofía.

- ع үà

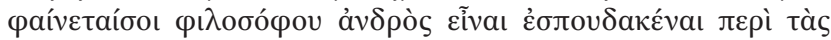

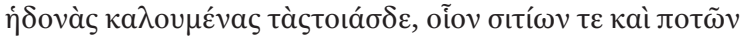

-

- Examina ahora, amigo, si compartes mi opinión en lo siguiente. Pues con eso creo que sabremos más de la cuestión que estudiamos. ¿Te parece a ti que es propio de un filósofo andar dedicado a los que llaman placeres, tales como los propios de comidas y de bebidas?

- $\quad$ En absoluto, Sócrates —dijo Simmias.

(PLATÓN, Fedón 64d)

\footnotetext{
${ }^{1}$ Trabajo realizado en el marco del proyecto postdoctoral financiado por FONDECYT no 3160230.

2 Docente e investigadora de la Pontificia Universidad Católica de Valparaíso, Valparaíso - Chile. 0000-0002-0676-1789 E-mail: valeria.campos@pucv.cl
}

http://dx.doi.org/10.1590/0101-3173.2020.v43n4.22.p343 


\section{INTRODUCCIÓN}

Tal como lo expresa Platón a través de Sócrates, el comer y el beber, así como también el sentido corporal asociado a dichos actos - el gusto -, parecen no ser preocupaciones propias de los filósofos. En efecto, en la historia de la filosofía occidental son pocas las reflexiones profundas que encontramos sobre la alimentación humana, así como son escasas también las discusiones que tienen como objeto el sentido del gusto. Ambas temáticas ocupan un lugar aparentemente periférico en los textos filosóficos de la antigüedad y modernidad, a veces incluso llegando a situarse en un lugar de exclusión explícita y no como simples omisiones. Platón fue el primero en considerar a la dietética como un área extra - filosófica, justamente por relacionarse directa y exclusivamente con las funciones corporales, que no tienen cabida en las discusiones propias de la ciencia suprema. En efecto, la alimentación está asociada a funciones biológicas y fisiológicas que nada tienen que ver con la

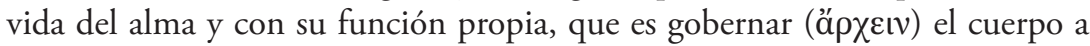
partir del razonamiento ${ }^{3}$. El gusto parece sufrir también una exclusión de la temática filosófica en varios niveles. Fundamentalmente, porque no se adecúa al discurso epistemológico a partir del cual es estudiada en la antigüedad la temática de los sentidos, pues ellos parecen ser sólo objeto de estudio directo cuando están vinculados al proceso de conocimiento; es desde esta constatación axiológica que fue posible establecer la clásica jerarquía que existe entre ellos: la vista es el más excelso, luego el oído, y sólo luego el tacto, el olfato y, en último lugar, el gusto ${ }^{4}$.

\footnotetext{
${ }^{3}$ Esta idea del gobierno (353d) incluye, sin duda, el control sobre el cuerpo, sobre sus pasiones y apetitos, problema que permite la única entrada posible de la alimentación en los discursos, a saber: como lo que debe ser subordinado a la soberanía de la Razón. Esta entrada es, así, uno de los elementos que permiten el trazado de la clásica frontera antropológica que separa bestias de humanos, recurso fundamental de la antropología filosófica tradicional. Sobre todo, la alimentación es opuesta a la vida filosófica, pues como dice Platón en la cita del Fedón, un filósofo no debe pensar ni en la comida, ni en la bebida, ni en el sexo (64d). En conclusión, puede decirse que la alimentación no es considerada por la tradición platónica como perteneciente al ámbito de la praxis, en la medida en que la acción humana está directamente relacionada con la función (épyov) propia del hombre, descrita posteriormente por Aristóteles, en continuidad con Platón, como la vida comandada por la parte del alma que tiene razón (Cf. Ética a Nicómaco, 1097b25 y ss.). En Aristóteles la cuestión de la alimentación se confunde fácilmente con el vicio asociado a ella, la glotonería, y se convierte en tema al criticarse todo criterio cuantitativo en la selección de los alimentos y en el proceso mismo de comer. En Ética Eudemia constata que la garganta es un órgano táctil, que en los glotones se parece a la de una grulla (1222a2240) -lo que nuevamente emparenta la alimentación con la animalidad.
}

${ }^{4}$ Esto está bastante claro en Platón, donde se establece que la vista es el sentido más apto para el conocimiento, porque su acción es la más parecida a la del intelecto respecto de los demás (Rep. 508b). En Timeo se repite la escena, afirmando que la vista es la que nos hace percibir todo el universo, incluyendo lo imperceptible del paso del tiempo, y es por esto la más excelsa (47a-b); también el oído 
Pero a pesar de todas estas exclusiones que marcan la norma del discurso de la filosofía desde sus inicios, el acto de comer y todo lo que le está asociado - cocinar, beber, degustar, digerir, defecar, vomitar, etc. - sí tienen un lugar clave en los textos filosóficos de todos los tiempos. Dicho lugar puede señalarse como un área de inclusión - exclusión ${ }^{5}$, que hace que la alimentación no pueda ser un tema central para la filosofía. Este espacio marginal, liminar, donde la alimentación se incluye en el discurso filosófico excluyéndose está relacionado con la oralidad con la que siempre, en filosofía, se ha asociado la lengua: lengua que se tiene tanto en la boca como también seńala aquello por medio de lo cual se producen las palabras y discurso mismo. Oralidad que señala un "llevarse a la boca", y que como tal está presente en cuanto recurso retórico en todos los momentos en que la filosofía hace del lenguaje su tema, como lengua, idioma, discurso, incluso como su propio discurso, el filosófico. Centrándonos en la filosofía de Jacques Derrida, abordaremos la cuestión de la alimentación en la filosofía señalando que su abordaje se constituye como una trópica, que hace del comer - en cuanto siempre un comer - algo - otro, un comer lo otro o comerse al otro - una figura clave de desplazamiento o

tiene una función epistemológica importante, porque es el medio por el que se adquiere el habla (47c y 75e), que es justamente lo que define al hombre como un animal con logos. La jerarquía se halla también en Aristóteles, quien pone a la vista en el lugar más excelente, porque el amor que tienen los hombres hacia ella es lo que manifiesta nuestra inclinación natural hacia el conocimiento (Metafisica I). En Del sentido y lo sensible se repite el gesto, porque la vista percibe el color y las formas, siendo el sentido que más cualidades distintivas permite captar (437a5-10); el oído es el sentido más importante para la educación por su vinculación al habla (437a10). En De Anima, si bien se consigna que la experiencia de todos los sentidos es indispensable para el conocimiento (427a18 y ss.), se establece una jerarquía de ellos partiendo desde el más básico: el tacto (porque todo ser sensible debe poseerlo) y luego viene el gusto (porque todo ser que se alimenta lo posee también). La vista y el oído son los sentidos superiores justamente porque están orientados al conocimiento, y esto debido a que son mediatos (419a10-25). Los sentidos inmediatos como el tacto y el gusto no contribuyen al desarrollo de la racionalidad, pues en la medida en que el objeto sensible no puede separarse del cuerpo del sujeto en su percepción, relativiza la experiencia perceptiva. La información que proporciona la vista es también de mayor calidad porque la forma de los objetos (lo que constituye su principio de inteligibilidad) es más accesible a la vista que a los otros sentidos (424a18-21).

5 Consideramos que dicho lugar está dado tanto por el modo de significar a la alimentación como un mero acto vital (y no una praxis) en el que no está involucrada la función racional del alma ni la vida del espíritu, por un lado, y por estar dicho acto estructuralmente ligado al placer del gusto y, con ello, a los vicios y desórdenes propios de la vida sensitiva, constituyéndose así como un obstáculo y una amenaza para la vida contemplativa, por otro. Notemos que esta doble exclusión es en realidad una estructura de exclusión-inclusión: se incluye a la alimentación dentro del discurso sólo para reprochársele su relación con el exceso, de modo de poder generar mecanismos de control más efectivos que el mero silencio respecto de ella. Ambas estructuras de exclusión parecen tener su génesis en las primeras investigaciones antropológicas de la filosofía griega, que distinguen al ser humano por recurso a una función propia enteramente racional, lo que a su vez le otorga una jerarquía explícita respecto de todos los demás seres no-racionales. 
transposición semántica para referir oblicuamente a temas que son, de hecho y de derecho, los más importantes para el discurso filosófico. Especialmente, nos referimos a los movimientos propios del alma o del espíritu: el pensamiento, la intencionalidad, la reflexión, la idealización, que han sido descritos muchas veces bajo la lógica de la asimilación, la incorporación, incluso directamente la nutrición ${ }^{6}$. Pero también para describir la discursividad misma, especialmente en su configuración como discurso filosófico, en cuanto remite a dicha estructura de traspaso de la frontera entre lo interior de un cuerpo y lo exterior a él, con todo lo que el proceso trae aparejado 7 . La alimentación se constituye así en una metáfora o, más precisamente, en una metonimia, tanto para el entendimiento como para el lenguaje y, por extensión, también para explicitar las dinámicas propias de la relación con el otro, la vida social y política.

En el siguiente trabajo, examinaremos esta función retórica que tiene el comer en los textos filosóficos a partir de los análisis llevados a cabo por Derrida en los seminarios inéditos dictados en Estados Unidos y Francia entre 1989 y 1991: Manger l'autre: Politiques de l'amitié y Rhétoriques du cannibalisme. Ambos seminarios se encuentran archivados en La colección especial de la biblioteca de la Universidad de California Irvine (UCI $)^{8}$, y forman parte de una serie de cursos dictados por Derrida en el período más extenso de

\footnotetext{
${ }^{6}$ Cf. Kant, I. (2014). Antropología en sentido pragmático. No son pocos los lugares en que Kant habla aquí de la comida y la bebida, pero destacamos especialmente este: "hay también un goce espiritual, que consiste en la comunicación de pensamientos, mas cuando nos es impuesto no resulta provechoso como alimento espiritual (Geistes-Nahrung, mi énfasis V.C.)” (p. 46, 158). De aquí se sigue el asco espiritual, dice Kant, que se nombra así en analogía con el asco corporal. Este último viene de ingerir alimentos que pueden resultar peligrosos para el animal, lo que general el vómito como reacción vital. El asco espiritual, por su parte, consiste en la repugnancia que encuentra el ánimo cuando se nos imponen ciertos pensamientos, por ejemplo, dice Kant, "la repetición continua de una misma clase de ocurrencias que pretenden ser chistosas o divertidas, incluso puede hacérsenos ingrata por esta monotonía" (p. 46, 158)

7 Cf. Fischler, 1995: 65-66. En interesante cómo la antropología cultural es de las escasas ciencias humanas que se han hecho explícitamente cargo del fenómeno alimenticio en sí mismo, y no es su relación con alguna otra esfera de la vida social. Las investigaciones de Claude Fischler sobre el tema lo llevan a plantear desde allí una suerte de principio de constitución del sí mismo, llamado "principio de incorporación": "el principio de la incorporación, es decir, el movimiento por el cual hacemos traspasar al alimento la frontera entre el mundo y nuestro cuerpo, lo de fuera y lo de dentro"

8 cf. http://hydra.humanities.uci.edu/derrida/uci.html. La citación de este seminario se llevará a cabo seńalando, en orden sucesivo, el número de caja en que se encuentra archivado el curso, luego el número de carpeta, luego la fecha completa (día/mes/año) en que fue dictada la clase en cuestión, para finalizar con la página establecida por Derrida dentro de esa clase. El curso Manger l'autre está archivado en la caja $\mathrm{n}^{\circ} 20$, en las carpetas 1 a 4 . El curso Rhétoriques du cannibalisme en la misma caja, carpetas 13 a 15 .
} 
1983 a $1991^{9}$, y que sirvieron de base para la edición y publicación del texto Politiques de l'amitié en 1994. Aun así, los seminarios nombrados referidos a la alimentación, al canibalismo y al tópico del sacrificio antropofágico solo ocupan un lugar marginal en dicha publicación, pues las referencias a estos temas son allí escasas. De ahí la preocupación no sólo por dar a conocer estos inéditos análisis que hace Derrida de la normatividad lógica y retórica de la filosofía a partir del tropo alimenticio, sino también de ponerlos en relación directa con las cuestiones abordadas en el texto del '94 e incluso de fijar un alcance más allá de ellas, hacia ideas que recorren su filosofía a lo largo de su producción textual.

Comenzaremos abordando la tesis de Derrida según la cual la lógica del discurso filosófico mismo se configura sobre una normatividad que es, en realidad, retórica. En efecto, Derrida sostiene que el discurso filosófico se construye a sí mismo mediante un cierto gesto de asimilación o introyección de normatividades discursivas ajenas, gesto que reproduce el movimiento mismo de la metaforicidad. Movimiento que, por responder directamente a una dinámica de incorporación, hace que la retórica de la alimentación se encuentra estructuralmente ligada a ella. Esto establece, en primera instancia, que el seminario del 89 - 90 no trata un tema aislado en la filosofía de Derrida, sino uno que lo preocupó desde los inicios de su pensamiento. Para ello, abordaremos en primer lugar los escritos directamente centrados en las funciones de la metáfora en los discursos filosóficos, como La mythologie blanche. La métaphore dans le texte philosophique de 1972 y Le retrait de la métaphore de 1978. Sin embargo, la tesis central de la metaforicidad filosófica como incorporación de lo ajeno la expondremos haciendo referencias acotadas a ciertos lugares de otro seminario inédito de Derrida, llamado Théorie du discours philosophique. La métaphore, del año 1969 - $1970^{10}$, que sirvió para

\footnotetext{
${ }^{9}$ Los seminarios que constituyen la base del texto del '94 fueron -según el mismo Derrida: La nationalité et le nationalisme philosophiques (1. Nation, nationalité, nationalisme [1983-84], 2. Nomos, Logos, Topos [1984-85], 3. Le théologico-politique [1985-86], 4. Kant, le Juif, l'Allemand [1986- 87]), Manger l'autre (Rhétoriques du cannibalisme) [1987-88]. Y también Sécret témoignage - questions de responsabilité [1989-93]. (Derrida, 1994:11). La instituciones norteamericanas en que fueron dictados son Yale, Cornell, City University of New York, UCI, School for Criticism and Theory at Dartmouth College, entre otras. También, muchos de los cursos fueron dados en Francia, en la École des Hautes Études en Sciences Sociales (EHESS).

${ }^{10}$ Cf. http://hydra.humanities.uci.edu/derrida/uci.html La citación de este seminario se llevará a cabo seńalando, en orden sucesivo, el número de caja en que se encuentra archivado el curso, luego el número de carpeta, luego el número de sesión (1 ra, 2da, 3ra, etc.), para finalizar con la página establecida por Derrida dentro de esa clase. El curso Théorie du discours philosophique está archivado en la caja $\mathrm{n}^{\circ} 10$, carpetas 8 a 15 .
} 
elaborar la publicación del '72. A partir de allí, se podrá establecer que existe una lógica retórica que es propia de la filosofía y que ésta puede describirse, a su vez, retóricamente a partir del acto corporal de la alimentación.

En continuidad con esta tesis, mostraremos cómo la filosofía no puede liberarse de esta retórica de la alimentación, pues ella designa, en última instancia, el movimiento mismo por el cual es producido el sentido lingüístico de todo discurso o, más específicamente, la discursividad en general. Esta cuestión es abordada en los seminario del 89 - 91 a partir de la dinámica misma del pensamiento, la comprensión y el lenguaje, en cuanto basados en un movimiento de auto - afección que puede describirse como gesto de introyección y asimilación de lo otro como condición de la ideación. Auto - afección que designa también en la filosofía de Derrida las condiciones de posibilidad de toda relación social con el otro, en cuanto se da bajo la forma originaria del duelo (deuil), tratada principalmente en texto posteriores como Spectres de Marx de 1993 y que también reproduce la estructura de la incorporación. Ambos tópicos están relacionados estrechamente en la filosofía de Derrida desde sus primeros escritos y ambos son abordados en los seminarios del 89 91 bajo la clave alimenticia, estrechándose aún más el vínculo entre ellos. En última instancia, estas exposiciones nos permitirán concluir que las metáforas sobre el comer comandadas por la figura del comer - al - otro (manger l'autre) integran un sistema de referencialidad semántica donde los desplazamientos y las relaciones diferenciales no solo describen en profundidad la estructura de los fenómenos en cuestión - la idealización, la verbalización, la relación con el otro -, sino que también explican el movimiento de la filosofía misma en cuanto comandado por una normatividad retórica. Se trata entonces de despejar otro camino para pensar la relación con el/lo otro - que sustenta el sentido y la función de la metáfora alimenticia - como aquello que impide toda clausura discursiva de la filosofía, en la medida en que señala un tropo de sustitución metonímica que le es fundamental y que deja al descubierto su dinámica estructural de envíos sin origen determinable.

\section{LA METAFORICIDAD DEL DISCURSO FILOSÓFICO}

El texto La mythologie blanche publicado en 1972 en Marges de la philosophie es uno de los escasos lugares donde Derrida expone su propia teoría de la metáfora y el lugar que esta tiene en el discurso filosófico. La radicalidad de las tesis ahí desarrolladas es tal que habría que ponerla del revés: 
pues más que explicar el lugar de la metáfora en el texto filosófico hace de la metaforicidad un momento estructural de este último. Por ello, a pesar del aparente lugar aislado que este texto sobre la metáfora parece tener en la filosofía de Derrida, es la base para una de sus temáticas más constantes. Tiene que ver con la hipótesis general sobre la forma retórica de los textos dada por la irreductibilidad de la escritura, en la medida en que todo el lenguaje, en su generalidad, no puede explicarse sino a partir de ella. Como se establece ya en De la grammatologie de 1967, pero incluso en Le voix et le phénoméne publicado el mismo año, es porque el signo gráfico contiene las notas conceptuales de todo signo en general, y está marcado por la imposibilidad de establecer una presencia plena de los fundamentos del sentido en él expresado - ya sea este fundamento la estructura interna del entre, el voilour - dire trascendental o la inmaterialdad del significado -, que la esencia misma del lenguaje se vuelve retórica, especialmente metonímica.

Esto se explica porque la escritura, tradicionalmente desplazada y condenada a ser un mero representante estático y estéril del habla que se piensa como lenguaje pleno, es utilizada estructuralmente por la filosofía como una metáfora - metonimia de la voz, cuya fuerza explicativa es tal que termina por suplantar, al querer solo suplementar, todas las funciones originalmente atribuidas al habla. Este es el centro de la teoría del suplemento de origen, tratado en De la gramatología especialmente en relación con los textos de Rousseau, y es lo que alza a la escritura y a su función retórica como el gran "peligro" para la filosofía. La escritura como suplemento del habla constituye así un uso metafórico - metonímico que es el único sentido propio posible para ella, tornándose así en tropo primero u originario (DERRIDA, 1967a:27, $22)^{11}$. El sentido "propio" de la escritura sería siempre la metaforicidad en sí misma, es decir, el de servir de suplemento semántico para lo único que puede - para la tradición onto - teológica - realmente dar lugar a la propiedad del sentido: el habla. Pero, en la medida en que la filosofía requiere de esta sustitución, que es específicamente metonímica - pues se usa lo exterior como

\footnotetext{
${ }^{11}$ Se cita, en primer lugar, la paginación de la edición francesa, y luego la de la edición española. Es necesario “[...] determinar el sentido 'propio' de la escritura como metaforicidad en sí misma”, dice Derrida. Tanto habla como escritura son en realidad metáforas: del movimiento del alma, de la dinámica del pensamiento. Tomadas en sentido propio son siempre exteriores. Pero el habla es de suyo más interior y natural que la escritura, por eso su sentido propio es el metafórico (es un archi-habla sin la cual no se concibe el pensamiento y, por lo tanto, el logos). Y la escritura se divide así entre buena (escritura del alma, comprendida en el interior de la naturaleza y de la ley) y mala. Esta división estaría dada por la determinación de la presencia como subjetividad, que seńalábamos. Pero la escritura es en realidad la metaforicidad misma, lo exterior tomado como interior, y en ese sentido incluye al habla.
} 
modo de nombrar lo interior -, señala incluso a pesar suyo las deficiencias constitutivas del habla - su falta de estabilidad, fijeza, trascendencia temporal, etc -, corriendo el peligro así que la metáfora reemplace por completo y estructuralmente a aquello que solo pretende nombrar por desviación retórica circunstancial.

En La mitología blanca, Derrida enfatiza esta condición estructural de la metáfora en el discurso filosófico, tomando como eje central la cuestión de la suplementariedad trópica que desencadena la escritura: no solo porque ella misma sea un suplemento - metafórico - del habla, sino porque al poder serlo muestra la imposibilidad misma que tiene la filosofía de trazar una línea divisoria que establezca una jerarquía ente habla y escritura. Con esto, además, sucumbe la pretensión de propiedad dada al sentido, y los desplazamiento semánticos se vuelven así la norma y la lógica misma de todo discurso, pues “[...] el nombre, particularmente llamado nombre propio, está siempre incluido en una cadena o en un sistema de diferencias. No deviene apelación sino en la medida en que puede inscribirse en una figuración" (DERRIDA, 1967a:136, 121). Estas ideas remiten a la cuestión del diferir o la operación de la différance, que Derrida trabaja desde sus primeros textos, y que apunta a la imposibilidad de establecer una clausura en la producción del sentido dada por una constitución trascendental de la experiencia. Dicha constitución trascendental, que Derrida explora siguiendo sobre todo a Husserl y al problema que la génesis introduce en la fenomenología $a^{12}$, no puede sostenerse como un proceso meramente interno de temporalización, sino que debe pensarse también a partir de un movimiento de espaciamiento ${ }^{13}-$ devenir espacio del tiempo - que instaura un momento de indeterminación absoluta en el origen del sentido. En efecto, en la medida en que dicha temporalización es descrita como "movimiento", se introduce ya una primera metáfora en la explicación; desde ahí "se habla metafóricamente, se dice «movimiento» en los términos de aquello que éste hace posible. Pero desde siempre se ha derivado ya a la metáfora óntica. La temporalización es la raíz de una metáfora que no puede ser sino originaria" (DERRIDA, 1993b: 95, 143). Esto tiene como consecuencia la imposibilidad de separar tajantemente el sentido literal del

\footnotetext{
${ }^{12}$ Cf. Campos, 2017

${ }^{13}$ Cf. La différance, en Derrida, 1972. Además, Derrida, 1967a 136, 121: "Lo propio del nombre no escapa al espaciamiento, ya sea que esté ligado por su origen a representaciones de cosas en el espacio o que permanezca atrapado en un sistema de diferencias fónicas o de clasificación social aparentemente desligado del espacio corriente".
} 
sentido figurado y así desde siempre "la metáfora trabaja al nombre propio" (DERRIDA, 1967a: 136, 121).

Sin embargo, el discurso filosófico, que utiliza de manera explícita metáforas para conseguir sus múltiples fines, no puede reconocer esta metaforicidad esencial de su discurso, y opera con una idea de metáfora que la reduce a un mero instrumento al servicio de la propiedad del significado, lo que a su vez es provocado por una "doble borradura": borradura del origen sensible de la nominación mediante una primera metaforización, la cual se borra también posteriormente para constituir el efecto de propiedad del nombre. Como dice Derrida (1972: 251):

El sentido primitivo, la figura original, siempre sensible y material $[\ldots]$ no es exactamente una metáfora. Es una especie de figura transparente, equivalente a un sentido propio. Deviene metáfora cuando el discurso filosófico la pone en circulación. Se olvida entonces, simultáneamente, el primer sentido y el primer desplazamiento. No se nota ya la metáfora y se la toma en sentido propio. Doble borradura. La filosofía sería este proceso de metaforización que se apodera de sí mismo. Por constitución, la cultura filosófica siempre ha estado gastada.

La filosofía borra así sus metáforas estructurales, les quita el carácter metafórico a partir de un uso continuado - de un ejercicio de usura - de ellas que "gasta" su semblante semántico de tropo y las constituye en nombre propios, i.e. adecuados a la naturaleza de lo que se dice. Esto implica que cada vez que usa metáforas de manera explícita, tiene que entonces intentar dominarlas. El discurso filosófico intenta lograr este cometido a partir de un principio mimético de identidad que hace de toda metaforización una simbolización: el tropo debe imitar a la palabra propia, debe mantener con ella una relación de identidad o al menos de semejanza, de modo que la pérdida semántica sea mínima y el peligro de diseminación del significado se mantenga a raya ${ }^{14}$. Esta idea hace que "La metáfora sigue siendo (reste), en todos sus rasgos esenciales, un filosofema clásico, un concepto metafísico" (DERRIDA, 1972:261, 259). Este control que se ejerce sobre la metáfora en filosofía la autorizaría a separarse tempranamente de la retórica, y a ponerse en una posición de superioridad respecto de ella.

\footnotetext{
${ }^{14}$ la metáfora como figura repite la lógica mimética de la estructura significado-significante: debe haber un parecido entre el significante y su significado; así, debe haber un parecido entre dos signos para que haya metáfora. En ambos casos, un término se subordina al otro, y el parecido se reviste de un semblante de "naturaleza" (Derrida, 1972: 255-256)
} 


\section{METÁfora FILOSÓFICA Y GASTRO - NOMÍA}

Sin embargo, tanto en este texto del ' 72 como en el seminario del 69 - 70 que es su base, Derrida se encarga de mostrar cómo la metaforicidad estructural del discurso filosófico no puede ser simplemente reducida, lo que implica a su vez que la metáfora no puede ser controlada por la función simbólica. En el seminario inédito del 69 - 70, Derrida establece de entrada que la lógica del discurso filosófico consiste, en efecto, en una lógica de la incorporación a partir de la metaforización. El discurso filosófico realmente no sería un discurso original, que se alzara sobre un dominio propio, sino que sería siempre un discurso derivado. Derivado pero, sin embargo, construido a partir de una apariencia de originalidad. En efecto, dice Derrida, el discurso filosófico se constituye mediante la "importación" de otros discursos ajenos, que son a su vez apropiados por la filosofía y que le permiten así reclamar una cierta primacía sobre los demás. Porque la lógica de la filosofía es una lógica de importación, digamos de introyección y de incorporación a la que le está asociada una total apropiación de lo ajeno por asimilación, es que puede relacionarse con todas las esferas discursivas sin reducirse a ninguna y, más aún, ponerse sobre ellas, en una suerte de lugar estratificado y jerárquico marcado por sus pretensiones normativas. En el seminario del $69-70$ Derrida (10, 8, 1ra, p. 5) dice:

El concepto de metáfora y de metaforización podría designar, de manera equívoca, a la vez uno de estos modelos de importación, una forma, entre otras, de estos préstamos o contrabandos y, simultáneamente, la forma general de la introyección de un elemento alógeno en el discurso filosófico [mi énfasis V.C.]. La metaforización podría ser considerada, en sentido estricto, como el tomar prestado por la filosofía cualquier figura del lenguaje ordinario o, en sentido amplio, como la forma general del desplazamiento por el cual la filosofía explota un discurso que le es extranjero, tomándolo prestado o asimilándolo, según un modo u otro, el léxico, la sintaxis, el contenido, el resultado, etc. ${ }^{15}$.

\footnotetext{
${ }^{15}[\ldots]$ je dirais par anticipation et très sèchement, que le concept de métaphore et de métaphorisation pourra designer, de manière équivoque, a la fois un de ces modèles d'importation, une forme, parmi d'autres, de ces emprunts ou de cette contrebande et, simultanément, la forme générale de l'introjection d'un élément allogène dans le discours philosophique. La métaphorisation pourra être considérée, au sens étroit, comme l'emprunt par la philosophie d'un figure quelconque du langage ordinaire ou, au sens large, come la forme général du déplacement par lequel la philosophie exploit un discours qui lui est étranger, en lui empruntant ou en en assimilant, su un mode ou un autre, le lexique, le syntaxe, le contenu, le résultat, etc.
} 
La lógica de la filosofía sería ella misma una lógica de incorporación de lo otro, de lo ajeno, que luego se somete a un proceso de asimilación donde todo lo que no puede reducirse es eliminado como resto. Esto sucede, dice Derrida, en consonancia con una suerte de actitud de la filosofía de imponer el método filosófico sobre toda otra metodología discursiva, que paradójicamente se lleva a cabo mediante el gesto de apropiación y asimilación de lo diferente. El ejemplo paradigmático para Derrida lo constituyen los discursos de la lógica y la matemática, que maravillan a la filosofía y producen así el impulso a transformarlas en sus herramientas, al precio de su total dominación y subordinación. Ejemplos de este movimiento son la lógica absoluta hegeliana, o la lógica trascendental kantiano - husserliana. Exponemos una cita a Hegel que fija esta tesis, al Prefacio de la 2 da edición de la Ciencia de la lógica: "[...] la filosofía no tiene por tanto la necesidad de ninguna terminología en particular, porque puede siempre traer las palabras de lenguajes extranjeros", complementa Derrida (10,8, 1ra, p. 12). La filosofía se define así como un proyecto de organización general del discurso, que opera mediante la introyección de discursos ajenos que se reducen en su alteridad, se asimilan y se jerarquizan, a partir de una legislación de última instancia ${ }^{16}$.

Por estas razones, la metáfora de la alimentación como movimiento de incorporación de lo extraño puede posicionarse como la forma más "propia" de describir la lógica del discurso filosófico. Pues comer como incorporación es de hecho un movimiento de traspaso (y de todas las figuras del trans - aquí nombradas) de la frontera que separa el exterior del interior, o de aquello que divide perfectamente cualquier espacio bien delimitado. Es por esta razón que:

Ni siquiera se puede decir que no hay un lugar más propio para situar la cuestión del límite entre el afuera y el adentro que la boca y el comer. Se debe decir que esta línea entre afuera y adentro, el entre en general no tiene ningún sentido y ninguna chance de aparecer afuera, si se puede decir así, de aquello que tiene lugar por, para y alrededor de la boca, etc. (DERRIDA, 20, 2, 29/11/89:100) ${ }^{17}$

\footnotetext{
${ }^{16}$ La philosophie est le projet d'une organisation générale des discours commandée par une législation de dernière instance $(10,8,1$ ra, p. 13)

17 “On ne peut même pas dire qu'il n'y pas un lieu plus propre à situer la question ou la limite du dehors et du dedans que la bouche et le manger. On doit même dire que cette ligne entre le dedans et le dehors, l'entre en général n'aucun sens et aucune chance d'apparaître en dehors, si on peut encore dire, de ce qui a lieu pour, par et autour de la bouche, etc".
} 
Dichos gestos de asimilación y jerarquización propios de la filosofía en cuanto discurso alzado, sostenido y organizado por una metafórica estructural que actúa como su misma ley de despliegue textual, son así nombrados "propiamente" mediante el tropo del comer. Y esto es posible sólo porque la filosofía opera en base a un lenguaje desfondado, en base a esa misma escritura que pretende denostar. Ello hace que la retórica sea un arte discursivo que se confunde a cada instante con la filosofía misma, pese a la necesidad histórica de establecer diferencias entre ambas. Esta confusión daría a la retórica un derecho inaudito, le otorgaría el título de ser "el foco mismo de todas las grandes cuestiones" (DERRIDA, b. 20, f. 1, 8/11/89: 4), toda vez que el problema sea la diferencia entre el sentido propio y figurado, entre el significado literal y el metafórico. La alimentación como figura del discurso, dice Derrida, es un lugar privilegiado para constatar la irreductible presencia de este problema, en la medida en que las formulaciones que de ella se utilizan en filosofía siempre remiten en última instancia a preguntas como estas: ¿qué quiere decir comer con los ojos? ¿qué quiere decir tener al otro en el estómago? ¿qué quiere decir devorar un libro ? ¿qué quiere decir digerir o no digerir no aquello que no es un alimento en sentido literal ? ¿por qué hablar de gusto, de disgusto o de vomitar ahí donde se habla de cosas, como una obra de arte por ejemplo, que no se dan a la facultad gustativa, sino a la vista o al oído? (DERRIDA, 20, 1, 8/11/89: 4) ${ }^{18}$.

Todos estos cruces problemáticos con el lenguaje metafórico a los que la filosofía está expuesta y que se muestran de manera patente en los recursos retóricos alimenticios, los hacen tan necesarios como peligrosos: necesarios para cubrir la falta de lo "propio" de la que adolece estructuralmente el discurso filosófico - que tiene que apropiarse siempre de lo ajeno -, y peligrosos mientras la filosofía quiera reducir la metáfora a su uso filosófico, no comprendiendo la forma general de la metaforicidad. Esta falta de comprensión no es una simple carencia de un saber específico, sino que señala la incapacidad de la filosofía para explicitar su propia lógica metaforizante, de descubrirse a ella misma como una máquina de metaforización, a partir de la incorporación de lo otro. Mientras esta re - flexión no se dé, la filosofía seguirá estando imposibilitada para dominar la metáfora (DERRIDA, 1972:272, 268). La alimentación seguirá siendo un recurso retórico que la filosofía pretende mantener en sus

\footnotetext{
${ }^{18}$ Qu'est-ce que manger des yeux ? Qu'est-ce qu'avoir l'autre sur l'estomac? Qu'est-ce que dévorer un livre? Qu'est-ce que digérer ou ne pas digérer ceci ou cela qui n'est pas un aliment au sens dit littéral? Pour quoi parler du goût, de dégoût ou de vomir là où s'agit de choses, par exemple d'ouvre d'art qui ne s'adressent pas à la faculté gustative mais seulement à la vue ou à l'ouïe, etc.?
} 
márgenes, pero que, como en un punto ciego para ella, amenazará siempre con volverse el nombre propio de su misma su lógica interna.

La tesis fuerte de fondo, entonces, sería más o menos así: la alimentación como contenido constante y permanente de un recurso retórico para la filosofía, según estas configuraciones normativas, aparece como la metaforización por excelencia de la metaforicidad estructural del discurso filosófico. Así como, para Derrida, la metáfora económica nombra de manera trópicamente "propia" a la metaforicidad en general (DERRIDA, 2017:79), la alimentación podría alzarse como la metáfora que nombre de modo trópicamente "propio" a la estructura discursiva misma de la filosofía en cuanto no separable ya de una retórica. Comer sería entonces un elemento de suplementariedad trópica (DERRIDA, 1972:261, 259) tan indomable como irreductible para la filosofía, lo que haría de su estructura retórica misma una forma alimenticia. En la medida en que el dominio de la filosofía sobre la metáfora no alcanza a ser completo, la filosofía no podría dominar, entonces, la metáfora que nombra su propia metaforicidad. Derrida dice, esta vez en el seminario Manger l'autre (1989 - 90), que el carácter retórico del discurso, incluido paradigmáticamente el filosófico en él, no sería solo la condición de posibilidad de la metaforización de la filosofía por la alimentación, sino que además la esencia misma de la retórica no podría ser explicada de modo "propio" más que por dicha metáfora, que hace que todo entre por la boca:

La retórica misma, como su nombre lo indica, es primero un arte de hablar (euro, rhéma, etc.) y luego, en tanto que experiencia de la palabra, oralización u oración de lo otro o por lo otro, alegoría, luego, consumidora de la alteridad. Antes de ser una de las figuras posibles de la retórica, la alegoría es, posiblemente, la retórica misma. Se puede así creer que el fin de la alegoría, que lleva al otro a la boca, que pone al otro en la boca, es la boca (DERRIDA, 20, 1, 8/11/89: 4$)^{19}$.

La alegoría sería la forma lingüística que nombra el discurso sobre lo

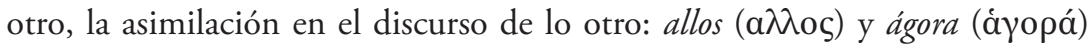
nombrando tanto el discurso sobre lo otro como lo otro en el discurso: el comer - lo - otro como introyección de lo otro para transformarlo en discurso.

\footnotetext{
19 "Rhétorique, donc, no seulement à cause de ce type de question mais parce que la rhétorique elle-même, comme son nom l'indique, est d'abord un art du parler (euro, rhéma, etc) et donc, entant qu'expérience de la parole, oralisation ou oraison de l'autre ou pour l'autre, allégorie, donc, consommatrice d'altérité. Avant d'être une des figures possibles de la rhétorique, l'allégorie, est peut être la rhétorique même. On pourrait ainsi croire que la fin de l'allégorie, qui porte l'autre a la bouche, qui met l'autre a la bouche, c'est la bouche"
} 
Lo otro es así llevado a la boca para poder ser dicho por la boca, a condición de su consumición. Es la retórica en cuanto siempre vinculada a esa operación de oralización del otro a través del lenguaje: el gesto mismo de la metáfora en cuanto mecanismo de aprehensión de lo ajeno, de préstamos y de asimilación, y que se expresa retóricamente también mediante el habla que sale de la boca. El movimiento de in - corporación de lo otro como modo de señalar la producción misma de la discursividad, y el paso por la boca señalando la oralidad de su resultado.

Estos intercambios semánticos entre la boca que come, la lengua que gusta, la boca que habla y la lengua que articula el lenguaje, se condicen perfectamente, por ejemplo - aunque no es un ejemplo entre otros, quizás - con el gesto platónico de hacer de la cocina la metáfora de la retórica, metáfora que constituye su nombre más "propio", en la medida en que no existe otro modo más que el alegórico para explicar su peligrosidad. La cocina, como acción de trasformación de las materias primas para convertirlas en alimentos, tiene como principal fin el producir placer - es decir, responder al apetito en lugar de gobernarlo. Platón la entiende como una forma degradada de la medicina, y la asimila así a la retórica (Gorgias 462d, 465c), en cuanto es una disciplina discursiva menor respecto de la dialéctica, pues no busca el conocimiento sino la mera persuasión. La comparación se da a través de la capacidad de producir placer, pues tanto la retórica como la culinaria no se preocupan de lo que sea bueno para el hombre, sino sólo de aquello que le produce placer y saciedad. Esta metáfora platónica no sería, para Derrida - aunque no es analizada por él en ninguno de sus textos -, ni contingente ni inocente: responde a una lógica del discurso que entrelaza esencialmente filosofía y retórica, habla y escritura, suplementariedad trópica y nombre propio. Y la forma de decirlo no es otra que a partir de una descripción alimentaria.

Más allá incluso de esta evidente alegorización alimenticia de la retórica por la cocina, el hecho de que ella se realice a partir del criterio del placer - pues la diferencia entre retórica y filosofía es que la primera tiene como fin producir placer - es lo que la determina desde ese mismo instante, al mismo tiempo, como arte del discurso $y$ como arte culinario, es decir, como una suerte de gastro - nomía. Pues el placer de la palabra tiene que ver con la capacidad que esta tiene de apropiarse y de asimilar el mundo, de transformar su naturaleza física en naturaleza virtual. Asimilación que se produce, ciertamente, a través de los orificios o, dice Derrida (2005:20), de los "sentidos" en general: para todos esos casos "la metonimia del 'bien comer' será siempre la regla", 
haciendo de la normatividad del discurso, justamente como señalábamos, una gastro - nomía. La afección que dicha transformación por asimilación produce en el alma o en el espíritu es lo que vincula con el acto de comer, en la medida en que el placer de la asimilación puede siempre ser dicho y descrito como alimentación. En última instancia, esto permite sostener la tesis de la metaforicidad estructural del discurso filosófico, en la medida en que "comer" no es un tropo cualquiera para nombrar la producción del discurso, su articulación a partir de una asimilación placentera del mundo, sino su tropo auténtico, su tropo propio, un suplemento originario: "cada término de la comparación es a la vez la figura y lo figurado, el movimiento trópico se mueve entre los dos sentidos" (20,13,07/11/90: 6). Esto no quiere decir sino que tanto el comer como el hablar son tropos y nombres propios a la vez, sin distinción posible. La filosofía, en tanto estructuralmente metafórica, es decir, en tanto originariamente retórica, es siempre una operación de incorporación de lo otro: es siempre una culinaria o, quizás más precisamente, un banquete (symposium).

\section{COMIDA PARA El PENSAMIENTO}

Si la metáfora alimenticia es capaz de describir la lógica del discurso filosófico de manera satisfactoria, se debe también a que puede describir el movimiento mismo del pensamiento, el acto de la comprensión tomado en su dinámica general. El seminario del 89 - 90, Comerse al otro (Manger l'autre) está completamente configurado en torno a esta posibilidad. Posibilidad que ya habíamos tenido la oportunidad de explorar a partir de la entrevista publicada el año 1989 (edición castellana de 2005) titulada Il faut bien manger. Le calcul du sujet. Interrogado por Jean Luc Nancy, Derrida (2005:20) instaura ya la posibilidad de un "comer" metonímico como el concepto mismo de experiencia dado, sin duda, por las anteriores constataciones de la estructura retórica del discurso filosófico, cuyo tropo más "auténtico" no es sino el de la incorporación gustosa - la alimentación. Así, dicho "comer" metonímico describe la operación de la subjetividad, en cuanto aprehensión de lo otro por el pensamiento, mediante la experiencia, simbólica o real, del comer hablar - interiorizar (DERRIDA, 2005:19). Esta operación, dice Derrida, es una es una lógica de re - apropiación de lo exterior al sujeto que instaura una "relación a sí como tal" como estructura de la subjetividad, que "es común tanto al idealismo trascendental como al idealismo especulativo como a la analítica existencial" (2005:10). Este movimiento puede adecuadamente 
describirse como una interiorización de la exterioridad, y es al mismo tiempo un fenómeno de afección (DERRIDA, 20,13,07/11/90:10 - 11) ${ }^{20}$ que opera como principio de constitución del sí mismo, o de la ipseidad de la identidad subjetiva.

Esta temática es también constante en la filosofía de Derrida, y puede rastrearse desde los escritos sobre Husserl (Le voix et le phénomène, 1967) y Heidegger, y luego hasta los análisis de Rousseau (De la grammatologie, 1967). En todos ellos, la lógica de la incorporación es descrita como un impulso auto - referente de auto - afección, a partir del cual la conciencia o la existencia se produce en relación consigo misma, y que en la tradición filosófica ha tomado la forma paradigmática de la experiencia del oírse - hablar (s'entendre-parler). Esta auto - afección, en su versión fono - céntrica o en cualquier otra, es para Derrida la condición de posibilidad del sentido en general, cuestión que la tradición metafísica entiende con independencia de la relación de la conciencia con una alteridad (DERRIDA, 1993b: 88 - 89) ${ }^{21}$. Diversos son los lugares en que Derrida enfatiza los problemas que la tesis de auto afección, cuando es tomada en forma pura, trae para toda teoría del sentido y para toda filosofía del lenguaje ${ }^{22}$. Esto comienza tempranamente, cuando muestra la imposibilidad que tiene la fenomenología husserliana de justificar la objetividad o tradicionalización (traditionalisation) del sentido sobre la sola

\footnotetext{
${ }^{20}$ Esta referencia corresponde al seminario que Derrida dicta el trimestre de 90-91, Rhétoriques $d u$ cannibalisme (archivos 13-14-15 de la caja 20).

${ }^{21}$ La auto-afección en la forma del oírse-hablar es para toda la tradición moderna y contemporánea, de Hegel a Heidegger, la condición para la conciencia en general. Y, por tanto, también la condición para la producción de sentido a través del lenguaje. Derrida dice en La voz y el fenómeno: "En tant qu'autoaffection pure, l'opération du s'entendre-parler semble réduire jusqu'à la surface intérieure du corps propre, elle semble, dans son phénomène, pouvoir se dispenser de cette extériorité dans l'intériorité, de cet espace intérieur dans lequel est tendue notre expérience ou notre image du corps propre. C'est pourquoi elle est vécue comme auto-affection absolument pure, dans une proximité à soi qui ne serait autre que la réduction absolue de l'espace en général. C'est cette pureté qui la rend apte l'universalité".

${ }^{22}$ Siguiendo a Duran (2015), Derrida "antes que reconocer en el esquema de la auto-afección una clave para comprender la subjetividad del sujeto, Derrida intentará mostrar en ella la paradoja que la atraviesa y que la constituye [...] La auto-afección grava el texto derrideano con el peso de una paradoja. La reproducción que no hace más que atormentar a la auto-afección desde su interior, se lleva a cabo mediante una repetición inmediata, "sin la ayuda de ninguna exterioridad", es decir, un exterior completamente dispuesto o disponible en su trascendencia. Pero, al mismo tiempo, sin la posibilidad de clausurar o saturar dicha trascendencia en un interior. Esta repetición inmediata posee una forma monstruosa: la única auto-afección es la que tiene que hacer pasar el afuera en el interior, sin someterlo o subsumirlo. Por ello es preciso advertir que, al mismo tiempo, la posibilidad misma de la autoafección descansa sobre su imposibilidad"
} 
base de una experiencia de repetición identitaria en el sí mismo ${ }^{23}$. Lo mismo es mostrado en los análisis de Rousseau, a partir de la idea de la escritura como suplemento del habla (DERRIDA, 1967a: 235, 208 y ss) ${ }^{24}$.

En el seminario del 89 - 90, la tesis de la auto - afección toma de modo determinante la forma de un movimiento de incorporación alimenticio. El mismo sentido de "comprender", en cuanto señala el gesto de aprehensión apropiadora de lo otro, puede entenderse en este sentido:

Apropiarse, asimilar, enunciar tomando en la boca u oralizar la cosa, es lo que no está jamás lejos del comer, y el/lo otro así comprendido se disocia difícilmente de esta instancia oral, de esta boca que incluye a los labios, un paladar, los dientes, una lengua, una glotis, de esta boca que no es una [...] de esta boca supuestamente una y que comprende, prende en ella o guarda en ella o rechaza, expulsa escupiendo lo que come, bebe, tiene hambre y sed, habla, a veces para preguntar por comer o para comer, beber, tragar, fumar, morder, masticar, succionar, besar, escupir al otro o a lo otro (DERRIDA, 20, 1, 08/11/90: 1) ${ }^{25}$.

Llevarse un alimento a la boca es la figuración retórica que por excelencia ha utilizado la filosofía para hablar este gesto de la aprehensión que está a la base de toda comprensión, e incluso de toda producción de sentido - y no hay

${ }^{23}$ Esta imposibilidad se debe a la necesidad que Husserl da a la escritura: "C'est la possibilité de l'écriture qui assurera la traditionalisation [mi énfasis, V.C.] absolue de l'objet, son objectivité idéale absolue, c'est-a-dire la pureté de son rapport aune subjectivité transcendantale universelle. Elle le fera en émancipant le sens à l'égard de son évidence actuelle pour un sujet réel et de sa circulation actuelle à l'intérieur d'une communauté déterminée" Pero a partir de esta posibilidad abierta por la escritura, amenaza también una crisis : abre la posibilidad de sobre-vivencia del sentido e la ausencia de todo sujeto, no dependiendo así de ninguna conciencia en particular o en general: "En virtualisant absolument le dialogue, récriture crée une sorte de champ transcendantal autonome dont tout sujet actuel peut s'absenter".

24 “[...] l'auto-affection se manifeste comme telle : elle laisse une trace de soi dans le monde. La résidence mondaine d'un signifiant devient inexpugnable. L'écrit reste et l'expérience du touchanttouché admet le monde en tiers. L'extériorité de l'espace y est irréductible. Dans la structure générale de l'auto-affection, dans le se-donner-une- présence ou une jouissance, l'opération du touchant-touché accueille l'autre dans la mince différence qui sépare l'agir du pâtir. Et le dehors, la surface exposée du corps, signifie, marque à jamais la division qui travaille l'auto-affection".

25 'S'approprier, s'assimiler, énoncer en prenant dans la bouche ou en oralisant la chose, ce qui n'est jamais loin de manger, et l'autre ainsi compris se dissocie difficilement de cette instance orale, de cette bouche qui comprend des lèvres, un palais, des dents, une langue, une glotte, de cette bouche qui n'est pas une [...] de cette bouche supposé une et qui comprend, prend en elle ou garde en elle ou rejette ou jette en crachant, qui mange, boit, a faim ou soif, parle, parfois pour demander a manger ou pour manger, boire, avaler, fumer, mordre, mâcher, sucer, baiser, recracher l'autre ou d l'autre ..." 
que ir más allá del mismo Platón para probarlo ${ }^{26}$. Porque toda comprensión como asimilación de lo otro se expresa también paradigmáticamente por la boca. Como hemos mostrado, los cruces entre la oralización de la palabra en la voz y la degustación - deglución que se da en la boca no son accidentales, y son el resultado de la metaforización estructural del discurso sobre el pensamiento y el lenguaje. En la entrevista de 1989, Derrida reconoce que esta asimilación del otro como movimiento fundamental de la comprensión, que nunca es lejana al comer, está vinculada además con una cierta "estructura sacrificial de los discursos", que corresponde a un matar (mise a mort) no - criminal, es decir, orientado a la ingestión, incorporación o introyección de un cadáver (2005:18). Una operación que ciertamente es de raigambre cultural y que puede determinarse como real toda vez que el cadáver es "animal", pero que no se reduce a la ingesta fáctica carnívora. Es también una estructura de tipo simbólico, pues el cadáver es, en la comprensión y en la relación con el otro, "humano". Esta operación sacrificial simbólica, de la que el vegetarianismo no nos salva (2005:17), apunta a un proceso de "interiorización idealizante" del otro, necesario para la constitución de su sentido - como alter - ego o Mitdasein, entre otras configuraciones - que está ligado a un pasaje por la boca (2005:9): tanto por la afección - sensible - que dicho proceso produce como por la necesidad de expresarla mediante la palabra (en cuanto parole).

Cuando esta estructura simbólica de la ingesta pretende asimilar ese "cadáver" sacrificial del otro de manera total, sin posibilidad de dejar restos indigestos, estaríamos ante la lógica de una auto - afección pura, cuyos problemas, como decíamos, no solo han sido mostrados por Derrida desde sus textos más tempranos, sino que constituyen la base crítica de toda la deconstrucción del logo - centrismo. El deseo de una pura digestión sin resto ${ }^{27}$,

${ }^{26}$ Como muestra Dalfen (2004), Platón utiliza la metáfora de la alimentación para referirse al deleite que produce atender a discursos orales bien construidos en muchos lugares de su obra (Timeo (27b78), Lisias (211c11), Fedro (227b6-7), República (352b4-7 y 354a13)) En los casos citados por él se relacionan estrechamente alimentación y discursividad, pues se habla de "festines y/o banquetes (estiasis) de palabras", con connotación claramente positiva.

${ }^{27}$ Cuestión que nunca puede ser realmente lograda. Siguiendo a Farrell (2006), si siempre que se come se come algo otro, entonces no puede haber digestión perfecta: "All you can eat is something othernot just any other, of course, but the nourishing other; yet ingestion is followed by excretion, the elimination of what in the nourishing other could not be assimilated; hence one cannot eat all of even the designated other, at least not without residue, not without what the French call les restes. There are always leftovers and scraps, not to mention the unmentionables, to be eliminated and then purged by water or purified by fire-inasmuch as purification is pyrification. Derrida's question: What is the structure and the system of waste, leftovers, rests" (p. 136). Cuestión tratada también por Derrida mismo en Glas (1974), la obra de Derrida dedicada a Hegel y Genet, está totalmente articulada en torno a la cuestión del restar (rester), como mantenerse, pero también del resto (reste) como lo que 
de una perfecta asimilación en cuanto reducción del cadáver del otro al cuerpo del sí mismo que se alimenta, es lo que vincula el logo - centrismo a un carno - centrismo: el dominio de una lógica de la relación de incorporación total, sin resto, de lo otro marcada por la necesidad de su sacrificio.

Sin embargo, dicha posibilidad de pura auto - afección, cuya interrupción por la alteridad de una exterioridad fue mostrada por Derrida en la necesidad de hacer de la escritura un suplemento necesario del habla, queda también entredicha por la imposibilidad de una total ingestión carnívoro sacrificial del otro. Todos los elementos aquí involucrados pueden ser descritos bajo la temática del comer carne buena o mala, de la prohibición de comer carne, la abstinencia de comer carne, de la sublimación y la substitución de la carne en una dieta carnívora, y de todas las temáticas que se resumen en la figura de la antropofagia y el canibalismo, dice Derrida $(20,1,08 / 11 / 89: 3)$ en el seminario del $89-90$. Un tópico que estaba ya contenido en la entrevista con Nancy, a propósito de la posibilidad de la deconstrucción del carno - logo - centrismo: no se trata, dice ahí Derrida (2005:20), de saber si es "bueno" o está "bien" comer al otro, y a cuál otro, pues "lo comemos de todas maneras y nos dejamos comer por él". Se trata más bien de cómo comer para comer bien cuando no se puede no comer, cuando hay que comer: se trata del il faut bien manger, entonces, como la normatividad general o incluso la ley de toda relación con el otro; ya en cuanto ley de la fenomenalización del otro a partir de la auto - afección, ya en cuanto ley de la comunión, la comunidad y la hospitalidad, de la acogida del otro. La ética de esta proposición es entonces una dietética, y no es lejana tampoco a la idea de una virtud de la política en cuanto gobierno, descrita por Platón como justicia: pues en la medida en que el gobierno del alma sobre el cuerpo es un dominio del deseo (órexis / ỏ $\rho \varepsilon ́ \xi \iota \varsigma)$, y sobre todo del deseo de comer y de beber (Rep. 439a y ss.), la ética es siempre originalmente una dietética ${ }^{28}$.

sobra o queda de una cierta operación sintética (1974:253), en cuanto residuo material, empírico, tan indeseable como peligroso (capaz de transformarse en una máquina castradora, máquina materialista, 54). La constatación primordial de Derrida en este texto, es que el pensamiento del resto no puede ser comprendido por la tradición filosófica que encuentra uno de sus momentos cúlmines en Hegel (1974:7), pues para Hegel el movimiento general de la Aufhebung no puede/debe dejar ningún resto, debe ser, por el contrario "total e infinita" (156).

28 "L'orexis, c'est d'ailleurs le nom pur désir en général. L'anorexique ce n'est pas seulement celui ou celle qui ne peut pas manger, mais au sens étymologique quelqu'un qui a perdu le désir, le nondésirant, le désir de manger étant ici le symbole du désir en général, ce que tous les désirs partagent entre eux" (20, 1, 08/11/89:20). 
A esta dietética se llega justamente describiendo cómo el comer al - otro (manger l'autre), "tropo auténtico" de la auto - hetero - afección como origen de la significación es también "tropo auténtico" de la relación social misma con el otro y, por tanto, la base de toda ética y política. Al explicitarlo en el seminario del 89 - 90, Derrida se ve forzado a hacer variar el manger l'autre en un manger avec l'autre, donde el "con" (avec) se vuelve así determinante. Porque comer - al - otro puede siempre intercambiarse con un comer - con - el - otro, y es esta variante la que hace del comer - al - otro la condición de posibilidad de la comunidad. Sin embargo, esta posibilidad no está dada sólo por la inmediata asociación que puede hacerse del comercon - otro con la partición o el compartir el alimento (partage du repas), que es en efecto la base de la una comunidad como la Cristiana, cuyo lazo está asegurado por dicha convivialidad. Pues no es sino el acto de repartir el pan de la eucaristía el que, mediante una función simbólica presenta el cuerpo de Cristo, opera "como alimento para nuestras almas y como lo que unifica la comunidad de los fieles" (DERRIDA, 20, 2, 22/11/89:64) ${ }^{29}$. Sobre todo en el paradigma Cristiano de comunidad, pero en general en cualquier otra, "La comensalidad, la convivialidad pacífica, la comunidad amistosa" (DERRIDA, $20,3,13 / 12 / 89: 124)$ se vinculan internamente, y bien puede decirse que no hay comunidad sin dicho sentarse juntos a la mesa.

Sin embargo, la cuestión del "con" del "comer - con" no puede zanjarse tan fácilmente. Pues el comer - con, si bien constituye una nueva formulación del "comer" metonímico con que la filosofía se explica a sí misma y la relación con cualquier - radicalmente otro (tout autre), no supone una distinción absoluta respecto del comer - al - otro. Como dice Derrida (20, 3, 13/12/89:124),

Pero "con" podría, por otro lado, en el suspenso de su sentido, designar también una modalidad del "comer al otro": en este último caso, se come con otro, como se dice que toma su desayuno con un café, pan, mantequilla

\footnotetext{
${ }^{29}$ Derrida says: "comme la nourritrre de nos âmes (ut) et comme (ut) la communité unie des fidèles". Derrida, following the authors of Port Royale again emphasizes that bread can cover-uncover the body of Christ specifically, in the Eucharistic ceremony, by the sentence "hoc est meum corpus". In a performative way, or trough a speech-act, a certain meaning is given to bread as a thing. How can we not consider the bread as the body of Christ in other contexts? Derrida says: "Ceci est du pain dans ce moment, ceci est mon corps dans cet autre moment', ces deux attributs se rapportant au même sujet, dans la confusion du même pronom démonstratif, les auteurs ne voient là aucune difficulté dès lors qu'on tient compte su temps, de, je cite, 'l'addition su temps' et du fait que l'esprit, je cite encore, 'suplée tout ce qui n'est pas exprimé'. L'addition du temps, cela ne veut pas dire simplement qu'on ajoute du temps ou que le temps s'ajoute ou se donne en plus, mais qu'on ajoute la considération su temps, la prise en compte de la différence entre ce maintenant ci et ce maintenant là, de cette différence dans la présence du présent"
} 
y mermelada, como se bebe vino con queso o come se cena con pescado crudo $^{30}$.

Comer - con el otro puede significar, a la vez, tanto comer acompañado del otro como comer al otro como acompañamiento de una comida. Cuestión de compañía y de acompańamiento, dice Derrida. Esto es lo que introduce en el centro de la preocupación alimenticia en su cariz político una relación de incorporación necesaria del otro, que en otros textos ha sido caracterizada como trabajo de duelo (travail du deuil). En el nombrado Politiques de l'amitié, pero sobre todo en Spectres de Marx de 1993, Derrida sostiene que la auto - afección como auto - hetero - afección - es decir, como auto - afección que nunca puede ser pura en tanto está determinada por la relación con una alteridad - puede ser entendida a partir de la figura del duelo: una relación con el otro en su muerte, a través de esa muerte, como la experiencia de la anacrónica temporalidad de su muerte. Este trabajo de duelo es también descrito como un trabajo de encriptación del otro, que refiere directamente a un movimiento de incorporación o introyección del otro (1993a:160) a partir de una experiencia afectiva que es también aprehensiva. Aprehender al otro, esto es, formalizar la experiencia afectiva de su encuentro, es para Derrida - y para una larga tradición que probablemente apunta a Hegel como un comienzo explícito - la base para la mismidad como ipseidad en todas sus posibles formas. Muchas veces Derrida enfatiza que el duelo es "originario", i.e. que no se reduce a una determinada afección, entre muchas otras que le ocurrirían a un ser ya constituido. La cuestión es más bien inversa, pues el duelo "instaura la relación conmigo mismo y constituye, en la différance - ni interna ni externa - que la estructura, tanto la egoidad del ego como toda Jemeinigkeit. La muerte del otro, esa muerte del otro en mí, es la única muerte nombrada en el sintagma 'mi muerte'[...]" (DERRIDA, 1998:123).

Esta última cita contiene dos elementos que permiten conectar la cuestión de la auto - afección con el duelo y, finalmente, también con el comer - al/con - otro: 1) el desplazamiento trópico que, por la naturaleza retórica del discurso filosófico, hace de la auto - afección un gesto de incorporación cercano a la alimentación; y 2) la referencia a ambas cuestiones en cuanto condiciones para la configuración de la ipseidad que, en un movimiento

\footnotetext{
${ }^{30}$ mis énfasis V.C. mais 'avec' pouvait d'autre part, dans le suspense de son sens, désigner aussi un modalité du 'manger l'autre' : dans ce cas là, on mange avec l'autre, comme on dit prendre son petit déjeuner avec du café, du pain beurré et de la confiture, comme on boit du vin avec le fromage ou comme on dine avec du poisson cru
} 
de auto - identificación, también se divide a sí misma. La incorporación en la forma del comer - al/con - otro es otro nombre para el duelo, y el duelo es otro nombre para esa auto - hetero - afección que constituye la estructura misma de la subjetividad y del sentido como anclado a ella; pero que lo hace fracturando la identidad, difiriéndola internamente. La relación con el otro es lo que comanda este movimiento introyectivo, que impide, por tanto, una completa asimilación. Así como toda alimentación deja restos in - asimilables, el duelo tiene que lidiar con la necesidad de encriptar al otro sin poder "ontologizar" sus restos, es decir, sin entender su muerte desde la idea de la muerte "efectiva" que la hace un contrario absoluto de la vida (Derrida, 2006:24). La figura del duelo originario, dice Derrida asimilándola directamente a la cuestión de la alimentación en el seminario del 89 - 90, implica la interiorización introyectiva o incorporativa del otro, que no le sobreviene después a una identidad ya constituida; por el contrario "ella está en el origen mismo de la identificación consigo, ella la vuelve posible fracturándola, dividiéndola, heterogenizándola" (20, 1, 08/11/89:24) $)^{31}$

\section{Conclusiones}

Las referencias a la boca, a lo que entra y sale por la boca y, por secuencia, lo que entra y sale también por otros orificios del cuerpo, que son los pasos fronterizos entre su interior y lo exterior, están presenten en muchos textos derridianos, sin haber sido todavía sistemtizados. Solo por nombrar algunos de estos lugares, señalaremos La palabra soplada, donde en un diálogo con Artaud se muestra que la función de organización de un cuerpo mediante sus órganos se produce siempre a partir de sus orificios: puertas de entrada y de salida, y entre ellos en especial la boca, por donde entran los elementos más sustanciales de la vida: el aire y el alimento (DERRIDA, 1967b:280). O Glas, de 1974, donde las temáticas de la lactancia, el vómito, los restos escatológicos, el gas (de la fermentación por aire) y la antropofagia son pivotales para todos el recorrido a través de Hegel y Genet. Como se establece también en el seminario del 89 90 , en la boca como entrada y salida se mezcla tanto el alimento como el aire, la materia del lenguaje y su virtualización misma a partir de la oralización ${ }^{32}$. En

\footnotetext{
31 "Donc l'intériorisation introjective ou incorporative de l'autre ne survient pas après coup à une identité constituée, elle est à l'origine même de cette indentification à soi, elle la rend possible en la fracturant, en la divisant, en l'hétérogénéisant".

${ }^{32}$ Quant à l'air qui passe par la bouche, quant au souffle ou à l'esprit, quant à la respiration, à la expiration, à l'inspiration, au soupir, soit que ce pneuma ou cette psyché orale assurent la vie,
} 
el presenta trabajo se ha mostrado cómo la alimentación como figura trópica puede nombrar al lenguaje mismo en cuanto siempre retórico - i.e. sustentado por una metaforización originaria -, sino también específicamente, a la lógica del discurso filosófico, en cuanto ella opera apropiándose de discursos ajenos. En ambos casos, el movimiento que comienza con un "llevarse a la boca", continua con la digestión y termina con la defecación, es un modo trópico adecuado para explicar la dinámica de la textualidad en general.

Esta tesis puede ampliarse así hasta el mismo "movimiento" de la comprensión como idealización de lo otro, e incluso hasta la relación con el otro a partir de la figura del duelo en cuanto originaria forma de dicha relación. "Pensar", en general y en todas sus formas (comprender, idealizar, aprehender, significar, hablar, sentir, relacionar, etc.) es siempre una incorporación de lo otro y un traspaso de la frontera que divide lo interior de lo exterior: es como comer. Pero no es un similitud lineal y continua, un traspaso analógico por isomorfía: no es que "comer" sea un significado familiar y "pensar" no, por lo cual nos sirve, en cuanto idea sensible, para entender una inteligible. Más bien, el sentido mismo del pensar debería obtenerse de la esencia de la alimentación adecuadamente pensada, y vice versa. El comer no es una metáfora del pensar (en sentido corriente) sino que pensar y comer deben entregarse mutuamente su sentido. He ahí el horizonte desde el cual, para Derrida, la alimentación como tropo filosófico se vuelve insoslayable para sus meditaciones. Siguiendo a P. Llored (2014) siempre pueda decirse que la deconstrucción es "una filosofía del canibalismo generalizado" 33 que, comiendo al otro - en una auto - hetero - afección, originalmente metafórica y enlutada -, intenta siempre también, a la vez, desestabilizar todas las figuras del sacrificio carnívoro: cuando estas operan a la base de una teoría fuerte de la soberanía como "autoridad del ipse, del sí mismo, del propio sí mismo” (Derrida, 2009: 68) 34 $^{34}$ ya sea directamente

l'oxygénation du sang, soit qu'ils conditionnent la vocalisation de la langue, ce n'est pas parce que nous allons parler de nourriture que nous l'oublierons (p. 3, $1^{\text {o }}$ )

${ }^{33}$ Llored destaca el nudo con el que debe lidiar la deconstrucción del logocentrismo, toda vez que está ligado con un sacrificio carnívoro d el/lo otro. En su texto describe un lazo inseparable entre voz, boca que come, falo, carne animal, de modo que puestas todas juntas solo pueden formar una tautología: "Tous ces mots sont tautologiques car ils proferent tous le même désir cannibale de manger l'autre, à la fois réellement et symboliquement, distinction qui perd sa signification dans cette structure sacrificielle de pensée, laquelle est vécue sur le mode ultraviolent de la dénégation autorisant et légitimant tous les euphémismes. Derrida nomme explicitement et courageusement le meurtre au cœur même du sacrifice carnivore comme opération centrale de ce cannibalisme généralisé, lequel acquiert toute sa puissance souveraine dans l'ordre du politique comme ordre sacrificiel dominant tout l'Occident".

${ }^{34}$ Derrida (2008: 92-93): “[...] el soberano aparecía casi siempre en la figura masculina del rey, del amo, del jefe, del padre de familia o del marido - de la ipseidad del ipse que, hace algunos años, al leer a 
en el terreno de lo político, como también en el del lenguaje, el discurso y hasta el pensamiento.

SALVATERRA, V. C. Eating what its other: rhetorics of eating: a reading of Jacques Derrida's unpublished seminar manger l'autre (1989 - 1990). Trans/form/ação, Marília, v. 43, n. 4, p. 343-368, Out./Dez., 2020.

\begin{abstract}
In the unpublished seminars given in the United States and France between 1989 1991, Manger l'autre: Politiques de l'Amitié and Rhétoriques du Cannibalisme, J. Derrida analyzes the rhetorical function that philosophical texts of the Western tradition give to the act of eating. As an act of incorporation of the alien and a gesture of trespassing the border between the exterior and the interior, eating has been used as a metaphor for the processes of understanding and idealization, as well as for the general dynamics of the relationship with other. Nevertheless, this tropic function of food reaches the very logic of philosophical discourse, as being also rhetorical. We analyze these functions by showing that they are structural to philosophy in general and special topics of Derrida's work in all his texts.
\end{abstract}

Keywords: Derrida. Cannibalism. Metaphor. Food. Philosophy.

\title{
REFERENCIAS
}

ARISTÓTELES. Del sentido y lo sensible. En Obras Completas, Tomo III. Buenos Aires: Bibliográfica Omega, 1967.

ARISTÓTELES. Tratado del alma. Madrid: Gredos, 1978.

ARISTÓTELES. Ética Nicomáquea, Ética Eudemia. Madrid: Gredos, 1985.

CAMPOS, V. Violencia y fenomenología. Derrida entre Husserl y Levinas. Santiago: Metales pesados, 2017.

DALFEN, J. Plato: Gorgias. Göttingen: Vandenhoeck \& Ruprecht, 2004.

DURÁN, C. La distracción de sí. Derrida y la auto - afección. Trans/Form/Açáo. vol.38 n.2 Marília May/Aug. 2015.

Benveniste, subrayamos que, en su etimología misma (véase la voz «hospitalidad» en El vocabulario de las instituciones indoeuropeas), implica el ejercicio del poder por parte de alguien que basta con designar como sí mismo, ipse. El soberano, en el sentido amplio del término, es aquel que tiene el derecho y la fuerza de ser y de ser reconocido como si mismo, el mismo, propiamente el mismo que sí. 
DERRIDA, J. Théorie du discours philosophique. La métaphore. Seminario inédito archivado en la Derrida Collection /Critical Theory Collection/ Special Collections and Archives/ UCI Library, California, USA. Box 20, files 1 - 4, 1969 - 1970.

DERRIDA, J. Manger l'autre: politiques de l'amitié. Seminario inédito archivado en la Derrida Collection /Critical Theory Collection/ Special Collections and Archives/ UCI Library, California, USA. Box 10, files 8 - 15, 1989 - 1990.

DERRIDA, J. Rhétoriques du cannibalisme. Seminario inédito archivado en la Derrida Collection /Critical Theory Collection/ Special Collections and Archives/ UCI Library, California, USA. Box 20, files 13 - 15, 1990 - 1991.

DERRIDA, J. Introducción a "L'origine de la géométrie” de Husserl. Paris: Presses Universitaires de France. 6ta edición, 1962.

DERRIDA, J. De la grammatologie. París: Minuit. Edición castellana de 2005, México: Siglo XXI. Traducción de Oscar del Barco y Conrado Ceretti, 1967a.

DERRIDA, J. L'écriture et la différence. Paris: Seuil, 1967b.

DERRIDA, J. Marges de la philosophie. Paris: Minuit. Edición castellana de 2010, Madrid: Cátedra. Traducción de Carmen González Marín, 1972.

DERRIDA, J. Glas. Paris: Galiée, 1974.

DERRIDA, J. Le problème de la genèse dans la philosophie de Husserl. Paris: Presses Universitaires de France, 1990.

DERRIDA, J. Spectres de Marx. L'État de la dette, le travail du deuil et la nouvelle Internationale. Paris: Galilée, 1993a.

DERRIDA, J. La voix et le phénomène. Paris : PUF - Quadrige, $1993 \mathrm{~b}$.

DERRIDA, J. Politiques de l'amitie. Paris: Galilée, 1994.

DERRIDA, J. Aporías. Morir - esperarse (en) los límites de la verdad. Traducción de Cristina de Peretti. Madrid: Paidós, 1998.

DERRIDA, J. Hay que comer bien. El cálculo del sujeto. Confines, n. 17, Buenos Aires. Traducción de Virginia Gallo y Noelia Billi, revisada por Mónica Cragnolini, 2005.

DERRIDA, J. Aprender a vivir por fin. Entrevista con Jean Birnbaum. Buenos Aires: Amo - rrortu. Traducción de Nicolás Bersihand, 2006.

DERRIDA, J. Seminario la bestia y el soberano. Volumen I (2001 - 2002). Buenos Aires: Manantial. Traducción de Cristina de Peretti y Delmiro Rocha, 2008.

DERRIDA, J. La retirada de la metáfora. En Phyché. Invenciones del otro. Buenos Aires: La Cebra. Traducción de Patricio Peñalver, 2017.

FARRELL, D. All You Can't Eat: Derrida’s Course, "Rhétorique Du Cannibalisme" (1990 - 1991). Research in Phenomenology. Vol. 36, pp. 130 - 180, 2006. 
FISCHLER, Claude. El (h)omnívoro. El gusto, la cocina y el cuerpo. Barcelona: Anagrama, 1995.

KANT, I. Antropología en sentido pragmatico. México: FCE, 2014.

LLORED, P. Comment ne pas manger l'autre. Rue Descartes no 82, Collège international de Philosophie, 2014

NIETZSCHE, F. Escritos sobre retórica. Madrid: Trotta, 2000.

PLATÓN. Diálogos II. Gorgias, Menexeno, Eutidemo, Menon, Cratilo. Madrid: Gredos, 1987.

PLATÓN. Diálogos III. Fedón, Banquete, Fedro. Madrid: Gredos, 1988a

PLATÓN. Diálogos IV. República. Madrid: Gredos, 1988b.

PLATÓN. Diálogos VI. Filebo, Timeo, Critias. Madrid: Gredos, 1992. 